\title{
A FORMAÇÃO DOCENTE: POR UMA PRÁTICA EDUCACIONAL LIBERTADORA ${ }^{1}$
}

\section{LA FORMACIÓN DOCENTE: POR UNA PRÁCTICA EDUCATIVA LIBERTADORA}

\author{
PROFESSOR FORMATION: FOR A LIBERATING EDUCATIONAL PRACTICE
}

\author{
Ademárcia Lopes de OLIVEIRA COSTA ${ }^{2}$ \\ Adriana RAMOS DOS SANTOS ${ }^{3}$ \\ Joseane de LIMA MARTINS ${ }^{4}$
}

RESUMO: A formação contínua e permanente dos docentes caracteriza-se como um espaço de reflexão, atualização, aprofundamento de saberes e práticas, interação com novos conhecimentos, desenvolvimento de experiências e ampliação de competências profissionais. Nesse contexto, insere-se o presente artigo, cujo objetivo é refletir sobre a formação docente para uma prática educacional libertadora a partir do pensamento freiriano. Para tanto, utilizamos uma abordagem qualitativa, fazendo uso da pesquisa bibliográfica e da pesquisa de campo, sendo esta última realizada através de um questionário com quatro professores que atuam nas escolas de ensino fundamental no município de Cruzeiro do Sul-Acre. Os resultados evidenciam que os professores abordam a necessidade da indissociabilidade entre teoria e prática nos cursos de formação, algo essencial para uma educação libertadora e crítica. Além disso, ressaltam que nas escolas não há espaço para discussões coletivas sobre problemas do cotidiano docente, residindo na formação continuada o momento para as trocas de experiências.

PALAVRAS-CHAVE: Educação. Educação libertadora. Formação docente.

RESUMEN: En el campo de la formación docente hay una búsqueda por nuevos modelos formativos que resultan muchas veces en propuestas de capacitaciones con paquetes cerrados. La formación continua y permanente de los docentes se caracteriza como un espacio de reflexión, actualización, profundización de saberes y prácticas, interación con nuevos conocimientos, desarrollo de experiencias y ampliación de sus competencias profesionales. En este contexto se inserta, el presente artículo, cuyo objetivo es reflexionar sobre la formación docente para una práctica educativa libertadora a partir do pensamiento freiriano. Para ello, utilizamos un abordaje cualitativo haciendo uso de la investigación bibliográfica y

${ }^{1}$ Este artigo foi publicado nos Anais da $2^{\mathrm{a}}$ Anped Norte, realizada na Universidade Federal do Acre (UFAC) em outubro de 2018. Versão atualizada e revisada.

${ }^{2}$ Universidade Federal do Acre (UFAC), Rio Branco - AC - Brasil. Docente do Programa de Pós-Graduação em Educação (PPGE). Docente do Programa de Pós-Graduação em Ensino de Humanidades e Linguagens (PPEHL). Centro de Educação, Letras e Artes. Doutora em Educação (UFRN). ORCID: http://orcid.org/0000-0001-95706660. E-mail: ademarciacosta@gmail.com

${ }^{3}$ Universidade Federal do Acre (UFAC), Rio Branco - AC - Brasil. Docente do Programa de Pós-Graduação em Ensino de Ciências e Matemática (MPECIM). Centro de Educação, Letras e Artes. Doutora em Educação (UFPR). ORCID: http://orcid.org/0000-0002-7402-2670. E-mail: adrianaramos.ufac@gmail.com

${ }^{4}$ Universidade Federal do Acre (UFAC), Rio Branco - AC - Brasil. Docente do Centro de Educação, Letras e Artes. Faculdade de Pedagogia. Doutoranda do Programa de Pós-Graduação em Educação (UFPR). ORCID: http://orcid.org/0000-0001-8922-768X. E-mail: joseanelimamartins@gmail.com 
de la investigación de campo. Los resultados evidencian que los profesores abordan la necesidad de la indisociación entre teoría y práctica en los cursos de formación, algo esencial para una educación libertadora y crítica. Además, resaltan que en las escuelas no hay espacio para discusiones colectivas sobre problemas del cotidiano docente, residiendo en la formación continuada el momento para los intercambios de experiencias.

PALABRAS CLAVE: Educación. Educación libertadora. Formación docente.

ABSTRACT The continuing and permanent formation of professors characterize itself as a space of reflection, updating, deepening of knowledge and practices, development of experiences and expansion of professional skills. In this context, the present article is inserted, whose objective is to reflect on professor's education for a liberating educational practice based on Freirean thought. In that way, we used a qualitative approach making use of bibliographic research and research field, the last one is made through a questionnaire with four professors acting on elementary schools in the municipality of Cruzeiro do SulAcre. The results stand out that professors approach the need of inseparability between theory and practice in formation courses, essential for a Liberating and critical education. Beyond that, stand out that in schools there is no space for collective discussions about daily professor's issues, residing on continuing formation the moment for exchange of experiences.

KEYWORDS: Education. Liberating education. Professors formation.

\section{Introdução}

Quando falamos em educação, referimo-nos ao conjunto de conhecimentos que a humanidade já construiu, ao acervo que cada indivíduo acumulou em função dos grupos aos quais pertenceu e pertence e de suas experiências pessoais adquiridas ao longo do tempo, acumulando, assim, valores e símbolos que têm como intencionalidade o desenvolvimento do ser social, histórico e concreto. Nesse contexto, o investimento na formação docente constituise em uma das estratégias fundamentais para que os objetivos visados pela educação sejam atingidos, sendo eles a construção de uma personalidade autônoma e reflexiva do educando perante a realidade social na qual se encontra inserido.

Desse modo, pensar a formação docente na atualidade é atentar para o fato de que esta deve atender aos desafios e necessidades postos. Para tanto, torna-se importante que o professor seja formado de modo que possa articular seus conhecimentos mediante ação reflexão teórico-prática. Pensada desse modo, a formação docente remete-se à reflexão da prática educativa voltada ao desenvolvimento da autonomia tanto do professor quanto do aluno.

Seguindo essa linha de pensamento, diversos são os estudiosos que se voltam a defender processos de formação continuada mais condizentes com as dificuldades e 
necessidades vividas pelos professores, suas carências, potencialidades e possibilidades. Dentre esses estudiosos, destacamos Paulo Freire, cujas ideias dialogam com diferentes questões contemporâneas e se mantêm voltadas à perspectiva da autonomia, da reflexão, da capacidade de prática e ação conscientes do professor e, consequentemente, dos estudantes, mostrando-se como um caminho possível para responder aos desafios da formação docente.

A formação de professores é um tema amplamente discutido nas obras de Paulo Freire, sob diferentes ângulos, em meio às tramas conceituais nas quais várias categorias do seu pensamento se entrelaçam, como o diálogo na relação teoria-prática, a construção do conhecimento, a democratização, dentre outras. Além disso, é defensor de uma educação libertadora fundamentada numa visão humanista crítica. Nesse enfoque, a formação e a aprendizagem não se limitam a um aumento de conhecimentos, mas influem nas escolhas e atitudes do indivíduo. A sua prática pedagógica, portanto, rejeita a neutralidade do processo educativo e concebe a educação como dialógica, uma educação que conduz o educando a um pensar autêntico e crítico da sua realidade.

É em meio a esse cenário que se insere a presente produção, cuja composição remetenos a refletir sobre a formação docente para uma prática educacional libertadora, tendo como base as ideias componentes do pensamento freiriano. Utilizamos como metodologia a abordagem qualitativa, fazendo uso da pesquisa bibliográfica e da pesquisa de campo, através do questionário como instrumento para o alcance dos dados empíricos almejados. Além disso, selecionamos três obras de Paulo Freire como suporte bibliográfico principal para nossas interpretações, são elas: Pedagogia da Autonomia (1996), Pedagogia da Esperança (1992) e Pedagogia do Oprimido (1987).

\section{Material e métodos}

Utilizamos como metodologia a pesquisa qualitativa, fazendo uso da pesquisa bibliográfica e da pesquisa de campo, sendo esta última realizada através de um questionário aplicado a quatro professores que atuam nas escolas de ensino fundamental no município de Cruzeiro do Sul-Acre. Esse tipo de pesquisa proporciona uma excelente oportunidade ao pesquisador de refletir sobre as informações publicadas em relação ao tema, de organizá-las, para, assim, construir seus próprios conceitos.

Consideramos, aqui, a pesquisa qualitativa como contextual, ou seja, voltada para a compreensão da realidade complexa, na qual várias vozes constituem o mundo em sociedade e os registros não estão prontos, pois serão gerados por meio da interpretação do pesquisador. 
Por isso, julgamos importante fazer uso da pesquisa bibliográfica, que consiste, conforme o entendimento de Marconi e Lakatos (1992), no levantamento de toda a bibliografia já publicada, em forma de livros, revistas, publicações avulsas e imprensa escrita.

Além do mencionado aporte, utilizamos o questionário para obtenção dos dados empíricos. Sobre esse instrumento de pesquisa, Dalberio e Dalberio (2009) afirmam que seu uso evita dúvidas ou incompreensões, ao passo que produz respostas curtas, objetivas e precisas, possibilitando a obtenção de informações com exatidão. Em vista dos elementos necessários ao nosso estudo, optamos por elaborar o questionário com questões abertas, que permitiram obter respostas livres, caracterizando de modo singular os posicionamentos dos participantes.

A pesquisa foi realizada com quatro professores que atuam nas escolas de ensino fundamental no município de Cruzeiro do Sul-Acre. A faixa etária dos participantes é de 29 a 42 anos, três desses docentes são do gênero feminino e um do gênero masculino. Quanto ao tempo de experiência no magistério, estes atuam entre dois e 12 anos nas escolas públicas.

Ressaltamos, assim, a importância da pesquisa para suscitarmos uma reflexão sobre a formação docente para uma prática educacional libertadora, pois a concepção problematizadora de educação proposta por Paulo Freire é oportuna para discutir não somente a formação docente, mas a concepção de formação enquanto um processo permanente de reflexão acerca da prática pedagógica com vistas às transformações.

\section{Formação docente: iniciando uma reflexão}

A formação docente continuada é um processo educacional no qual o professor destaca-se como agente e sujeito de sua prática, além de ser o responsável pela construção e reconstrução do conhecimento, promovendo o desenvolvimento cognitivo dos discentes. Diante disso, essa formação deve possibilitar ao docente trabalhar com o conhecimento de um modo que transcenda o ensino e que alcance uma atualização científica, pedagógica e didática que lhe permita criar espaços de participação, discussão e reflexão em suas próprias atividades profissionais. Desse modo, proporcionando aos alunos condições de lidar com as realidades sociais em que se encontram inseridos, sendo capazes de analisá-las e de agir de modo autônomo e consciente sobre elas. Sendo assim, o ensinar reveste-se de um teor político e, por conseguinte, inexistente sem o aprender, tal qual este também se anula sem aquele.

É nessa perspectiva que Freire (1996) nos lembra do caráter social que acomete homens e mulheres e que, ao longo do tempo, propiciou a estes saber o sentido do ensinar, 
bem como as inúmeras possibilidades e condições que esse ato demanda, sobretudo quando o objetivo se volta à conscientização e libertação dos sujeitos.

Nesses trâmites, o autor nos impulsiona a refletir sobre a importância dos saberes pedagógicos para a prática educacional, uma vez que já não basta àquele que ensina a aquisição e o domínio do conhecimento acumulado, mas toda a contextualização que o envolve, todos os propósitos que o abarcam e a que se destina. Com isso, a pedagogia proposta por Paulo Freire caracteriza-se, então, pelo caráter da reflexividade e da transformação. Logo, ser professor em meio a esses parâmetros implica um compromisso constante com as práticas sociais e com a capacidade de atuação e mudança em meio a estas.

É na consideração desse entendimento que o referido autor ressalta:

A educação constitui-se em um ato coletivo, solidário, uma troca de experiência em que cada envolvido discute suas ideias e concepções. A dialogicidade constitui-se no princípio fundamental da relação entre educador e educando. O que importa é que os professores e os alunos se assumam epistemologicamente curiosos (FREIRE, 1996, p. 96).

Mostra-se notório, a partir de elocuções como essas, que a educação pensada numa perspectiva libertadora deve acontecer por meio de uma prática mediada pelo diálogo e pela valorização da cultura dos sujeitos, sobretudo acreditando-se que a educação é uma forma política de transformar a sociedade ou de aflorar caminhos que impulsionem os sujeitos a se conscientizarem sobre seus papéis nesse cenário, sendo capazes de buscar mecanismos mais justos e igualitários de vivência social. O diálogo, portanto, é uma categoria central da construção do conhecimento e deve atravessar cada etapa da formação, evitando o risco de que ela se torne um processo de educação bancária, que serve à manutenção da ordem social estabelecida.

Para Freire (1996), o diálogo é o caminho que possibilita a interação e a construção de um mundo melhor e mais justo, centrado em uma "práxis" que inclui e que não se conforma com a reprodução, mas com a produção coletiva, crítica, política, consciente e reflexiva, em que a educação aparece como espaço impulsionador da construção e da transformação.

Esse entendimento propõe a superação do paradigma tradicional de ensino em que o aluno se traduz como um ser passivo e sem capacidade de intervenção no seu espaço. E, ao invés da transmissão de conteúdo, esse ensino reflete-se em sua construção, discussão, análise, interpretação e uso consciente, o que evidencia o aprender e o ensinar como atos diretamente vinculados à pesquisa, à busca, à descoberta. É com essa compreensão que o autor defende a ideia de que "não há ensino sem pesquisa e pesquisa sem ensino. Esses que- 
fazeres se encontram um no corpo do outro" (FREIRE, 1996, p. 32), de modo que, enquanto se ensina, continua-se buscando, reprocurando, indagando e, para isso, também pesquisando, o que permite conhecer o novo e com ele desenvolver sempre outras descobertas (Op. cit.).

Evidencia-se, assim, a responsabilidade do profissional de educação diante da sua tarefa de pesquisador na busca de conhecimentos que acompanhem as mudanças por que passa a sociedade, de modo que possa oferecer um ensino condizente com as capacidades então exigidas. A constante formação do docente mostra-se, frente a isso, como base essencial de seu fazer, de modo que sua prática possa refletir, além da superação da perspectiva tradicional sobre os processos de ensino e de aprendizagem, o impulso à pesquisa e à descoberta também para os alunos. Nesses termos, destaca-se, em especial, o perfil de problematizador da aprendizagem, além de aberto a novas experiências, como centro da constituição profissional.

Essa definição contrapõe-se, portanto, à perspectiva da educação bancária também discutida por Freire (1987), cuja ocorrência destrói qualquer condição de autonomia e libertação dos indivíduos; ao contrário, corresponde a uma restrição à capacidade de conscientização destes. A esse respeito, pronuncia-se o autor: "Na visão "bancária" da educação, o 'saber' é uma doação dos que se julgam sábios aos que julgam nada saber. Doação [...] que constitui o que chamamos de alienação da ignorância, segundo a qual esta se encontra sempre no outro" (FREIRE, 1987, p. 33).

Nessa perspectiva, uma pedagogia libertadora não se constitui apenas na mudança de metodologias e estratégias de ensino, mas na forma como as ações educativas são entendidas, concebidas e, em meio a isso, na capacidade de formação do ser social considerando-se todos os aspectos que o tomam: políticos, culturais, econômicos, cognitivos, sociais, dentre outros.

Sendo assim, Freire (1992) defende que o professor realmente ensina quando

[...] refaz a sua cognoscitividade na cognoscitividade dos educandos [posto que] ensinar é assim a forma que toma o ato de conhecimento que o(a) professor(a) necessariamente faz na busca de saber o que ensina para provocar nos alunos seu ato de conhecimento também. Por isso ensinar é um ato criador, um ato crítico e não mecânico. A curiosidade do (a) professor (a) e dos alunos, em ação, se encontra na base do ensinar-aprender (FREIRE, 1992, p. 41).

É em vista disso que se impõe a necessidade de uma formação continuada centrada na realidade, nas vivências e aspirações do professor, uma vez que por esse caminho torna-se mais propícia a condição para que este reflita sobre o seu fazer e permita-se apreender 
percursos outros, cujas ausências ainda se mostrem reluzentes em sua constituição profissional.

No entender de Freire (1992, p. 55), "aquele ou aquela que ensina aprende e aquele ou aquela em situação de aprendiz, ensina também”, ou seja, ao consideramos uma formação docente devemos sempre lembrar de todo o cenário que compreende o fazer do professor e, em meio a ele, dos aprendizados e das carências daquele que, no seu dia a dia, encontra-se na condição de eterno mestre e aprendiz.

\section{Resultados e discussões}

Conforme já anunciado, os resultados aqui descritos derivam de um questionário aplicado a quatro docentes que atuam no ensino fundamental no município de Cruzeiro do Sul/Acre. Esse instrumento de pesquisa foi elaborado unicamente com questões abertas, compreendendo aspectos como a formação docente e a atuação profissional. Para as análises, utilizamos como respaldo as obras anteriormente anunciadas de Paulo Freire.

$\mathrm{Na}$ interpretação dos dados obtidos, em relação à formação docente, pudemos perceber que, para os participantes, todos os processos de formação vivenciados podem ser qualificados como positivos, ainda que, em alguns casos, não atinjam completamente suas aspirações. Nessa perspectiva, todos contribuem para um norteamento sobre o "ser professor", pautado no embasamento teórico-prático que proporcionam, favorecendo a construção de novas ideias para a atuação em uma sala de aula. Nesses termos, defendem firmemente a unicidade entre a teoria e a prática como base aos cursos de formação.

Sobre isso, os professores argumentam que os problemas reais da sala de aula precisam ser expostos nas formações para que possam pensar em possibilidades de solução. Além disso, ter a prática como referente direto para contrastar com os estudos teóricos favorece grandemente a condição de se repensar o fazer, de se desenvolver novos conhecimentos e, geralmente, de se assumir novas posturas e ideais.

Esse posicionamento, em meio à abordagem teórica abordada nesta produção, remetenos à ideia de que somente numa interação dialógica entre teoria e prática, ambas mutuamente se influenciando e tendo como respaldo as dificuldades, necessidades, buscas e anseios dos sujeitos envolvidos (professores, alunos, comunidade), bem como a estrutura que compõe a escola, é possível alcançarmos um processo formativo de ampla natureza. Desse modo, “a reflexão crítica sobre a prática se torna uma exigência da relação Teoria/Prática sem a qual a teoria pode ir virando blablablá e a prática, ativismo" (FREIRE, 1996, p. 12). 
O autor, portanto, considerava inadmissível a separação entre teoria e prática na atuação e formação docente, pois, segundo ele, o conhecimento teórico isolado não possibilita a reflexão crítica sobre o mundo, o que impõe barreiras à transformação da sociedade. Considerar a formação dos professores, especialmente daqueles que atuam nos anos iniciais, implica o reconhecimento de que o percurso formativo deve propiciar situações em que a teoria seja abordada criticamente e a prática a ela relacionada seja vivenciada de modo que possibilite a (re)criação de conhecimentos e de opções práticas para a abordagem do conhecimento em sala de aula.

Vale ressaltar que, dentro dessa abordagem, quando questionados sobre como definem sua prática educativa, todos os participantes se intitularam como embasados na tendência progressista, porém, não ampliam tal afirmação ou mencionam elementos que definam características específicas dessa concepção. Em suas justificativas, essa tendência é assumida pelo fato de valorizarem as experiências dos alunos vividas na família e no grupo social do qual fazem parte. Além disso, argumentam que a partir desses conhecimentos prévios desenvolvem os seus objetivos educacionais, criando possibilidades de participação, atuação e construção por parte dos educandos. Os professores destacam, ainda, o distanciamento que têm das posturas tradicionais ao considerarem o aluno no centro do processo ensinoaprendizagem.

Conforme exposto, mostra-se certa fragilidade conceitual por parte dos participantes no que se refere à tendência progressista. Ainda assim, podemos observar claramente uma necessidade de distanciarem-se dos aspectos que definem a pedagogia tradicional, alegando que a verdadeira aprendizagem ocorre num processo dialógico. Essa realidade, ainda que possa mascarar a real compreensão dos participantes sobre essas abordagens de ensino ou apenas a repetição de um discurso amplamente circulante no meio educacional, demonstra que, no que se refere à prática profissional, esses participantes assumem a necessidade de que as ações ocorram vinculadas à realidade e às aspirações dos aprendizes, num processo dialógico entre o ensino, os educandos, suas realidades e os conhecimentos a serem trabalhados. Com isso, o sentido da dialogicidade se faz presente e consoante com a definição de Freire (1996), quando este afirma que:

[...] nas condições de verdadeira aprendizagem os educandos vão se transformando em reais sujeitos da construção e da reconstrução do saber ensinado, ao lado do educador, igualmente sujeito do processo. Só assim podemos falar realmente de saber ensinado, em que o objeto ensinado é apreendido na sua razão de ser e, portanto, aprendido pelos educandos (FREIRE, 1996, p. 13). 
Outro tema abordado nas respostas dos participantes foi referente às experiências compartilhadas. Segundo eles, a troca de informação é enriquecedora durante as capacitações por proporcionar respostas não apenas às questões de âmbito geral, mas também singulares à prática de cada um. Destacam, ainda, que costumam fazer uso do diálogo não só nos encontros formativos, mas, também, na própria sala de aula. Com esses discursos, remetemonos mais uma vez à questão da dialogicidade como aspecto central da educação libertadora. $\mathrm{Na}$ argumentação do autor:

O diálogo torna-se a essência de uma educação humanizadora e se constitui como um fenômeno essencialmente humano, realizado pelas pessoas por meio da palavra, a partir de duas dimensões: a ação, para a transformação e não alienação e a reflexão, atrelada à conscientização crítica e não alienante. Assim, a palavra não deve ser um privilégio de poucas pessoas, mas direito de todos os homens e mulheres (FREIRE, 1987, p. 78).

Reforça-se, com isso, a percepção de que o diálogo deve fazer parte do ensino como meio para desenvolver o pensar e o agir tanto do professor quanto do aluno, pois é nesse momento de dialogicidade que professores e educandos constroem novos conceitos, conhecimentos e reflexões que podem ser utilizados em seu cotidiano. Nessa direção, o ato de ensinar envolve valores, sentimentos, representações, crenças e expectativas do professor sobre seu trabalho e sobre os alunos com quem convive. Além disso, o professor deve ser mais que um mero transmissor de conhecimentos e informações, deve ser um educador situado no seu contexto histórico, com escolhas políticas e ideológicas conscientes, engajado na luta por uma educação crítica e libertadora.

Ampliando essa concepção, Freire (1987) ressalta que não há outro caminho senão o da prática de uma pedagogia humanizadora em que a liderança revolucionária, em lugar de se sobrepor aos oprimidos e continuar mantendo-os como quase "coisas", com eles estabelece uma relação dialógica permanente. A relação pedagógica deve estar fundamentada, portanto, na troca, no diálogo, na compreensão entre professor e aluno, fatores estes considerados por Freire como essenciais para a superação do autoritarismo em sala de aula.

Essa afirmação remete-nos, assim, à ideia de que o professor se educa e se forma no decorrer de sua existência, permanentemente (re)construindo-se. Desse modo, formando-se e transformando-se nas e pelas relações que estabelece em seu contexto, na interação com seus pares, transformando sua própria maneira de ser, sentir, (re)agir no convívio social.

Em vista disso, consideramos que, por mais que a formação inicial se dê de forma abrangente, sistemática e aprofundada teoricamente, não caberá apenas a esta a plenitude da 
ação docente, tendo em vista que a cotidianidade da sala de aula gesta-se vinculada a contextos diversos e, por isso, mostra-se suscetível a situações e ocorrências variadas que exigem conhecimentos abrangentes, atitudes e procedimentos específicos do professor, direcionados aos problemas que vão surgindo ao longo de sua prática.

$\mathrm{Na}$ atualidade, ainda percebemos a existência de cursos formativos que reduzem a formação docente ao treinamento técnico e não à formação crítica. A concepção freiriana busca a transformação, preocupa-se com uma formação crítico-reflexiva, desafiando o docente a pensar criticamente a realidade social, política e histórica em que está inserido. Nessa perspectiva, acreditamos que o docente que tenha consciência da necessidade de formação contínua ao longo da sua trajetória profissional, que se percebe com um profissional inacabado, e que necessita, portanto, de se inserir permanentemente em um processo formativo, reconhecendo-se como um eterno aprendiz, requer uma formação que tenha como base a análise reflexiva e crítica da sua prática.

\section{Considerações finais}

A pesquisa realizada propôs-se a fazer uma reflexão sobre a formação docente a partir da perspectiva freiriana. Diante do exposto, observamos que uma formação docente que vise à constituição de um indivíduo com capacidade para refletir criticamente, pressupõe explorar a natureza social e histórica presentificada nas relações entre as pessoas e suas formas de agir diante dos problemas. O professor deve ser alguém que tenta integrar-se num processo de mudança e que busca interpretar os seus próprios valores como forma de tomar consciência de si. Para tanto, é preciso uma formação docente que o leve a ser um problematizador na sala de aula e não apenas reprodutor ou mediador do conhecimento; que o impulsione a ter um compromisso político e a preocupar-se com a natureza do conhecimento a ser apropriado pelo aluno. Não basta interpretar e explicar a realidade que ronda a docência, é preciso nela intervir, reduzindo a distância entre teoria e prática.

Nesse entendimento, os dados deste estudo evidenciam que a formação docente baseada na perspectiva freiriana se estabelece e se institui no cotidiano, na construção do conhecimento profissional docente, superando o conhecimento racional técnico. Assim, os atos de pensar/repensar, fazer/desfazer cotidianamente presentes na sala de aula não podem ser vistos apenas como dificuldades corriqueiras, mas como espaços para reflexão, ação e descobertas, uma vez que constituem um trabalho que ainda está em construção e que, por sua natureza, demanda muitos acertos e erros. 
Imperiosa se faz a afirmação de que não é possível encontrar um modelo de formação para cada problema apresentado. Acreditamos, apenas, que as contribuições teóricas de diferentes naturezas nos propiciam pensar um pouco mais sobre o todo, permitindo-nos (re)construir discursos e soluções singulares que possam amenizar as inquietações que tomam todos aqueles que se encontram na prática da docência. Amparamo-nos, portanto, nessa ideia quando encontramos em Paulo Freire explicações bastante consideráveis sobre muitas das nossas próprias indagações, bem como naquelas tecidas pelos participantes de nossa investigação.

Asseveramos que uma proposta formativa fundamentada no pensamento freiriano poderá contribuir para uma formação e atuação docente emancipatórias, pois acreditamos que é possível uma formação na qual o papel do professor não se reduza à mera execução de predeterminações pedagógicas, mas que este se assuma como sujeito da sua prática, a qual deve imbricar-se de reflexão e crítica. Sendo assim, entendemos que o pensamento de Freire pode subsidiar a orientação de novos caminhos para uma formação continuada comprometida com ações educativas coerentes com a formação humana e em uma perspectiva crítica, reflexiva e libertadora.

\section{REFERÊNCIAS}

DALBERIO, Osvaldo; DALBERIO, Maria Cecília Borges. Metodologia científica: desafios e caminhos. São Paulo: Paulus, 2009.

FREIRE, Paulo. Pedagogia da autonomia: Saberes necessários à prática educativa. 25. ed. São Paulo: Paz e Terra, 1996.

FREIRE, Paulo. Pedagogia da esperança: um reencontro com a pedagogia do oprimido. 17. ed. Rio de Janeiro: Paz e Terra, 1992.

FREIRE, Paulo. Pedagogia do oprimido. 17. ed. Rio de Janeiro: Paz e Terra, 1987.

MARCONI, Marina de Andrade; LAKATOS, Eva Maria. Metodologia científica. Atlas: São Paulo, 2011. 


\section{Como referenciar este artigo}

OLIVEIRA COSTA, Ademárcia Lopes de; RAMOS DOS SANTOS, Adriana; LIMA MARTINS, Joseane de. A formação docente: por uma prática educacional libertadora. Revista Ibero-Americana de Estudos em Educação, Araraquara, v. 15, n. 3, p. 1193-1204, jul./set. 2020. e-ISSN: 1982-5587. DOI: https://doi.org/10.21723/riaee.v15i3.12511

Submetido em: 07/05/2019

Revisões requeridas em: 29/08/2019

Aprovado em: 24/10/2019

Publicado em: 20/02/2020 